\title{
A comparative study of Brass-V Drape and standardised visual estimation of blood loss during vaginal delivery - a single-observer study
}

\author{
Gulab Singh', Vijay Singh², Shibu Sasidharan², Suneeta Singh ${ }^{3}$, Abdul Naseer ${ }^{4}$, Babitha $\mathrm{M}^{5}$, \\ Harpreet Singh Dhillon ${ }^{6}$
}

\author{
'Department of Obstetrics and Gynaecology, Umaid Hospital, India \\ ${ }^{2}$ Department of Anaesthesiology and Critical Care, MONUSCO, Congo \\ ${ }^{3}$ Department of Obstetrics and Gynaecology, MONUSCO, Congo \\ ${ }^{4}$ Indian Navy, India \\ ${ }^{5}$ Department of Radiodiagnosis and Imaging, Alchemist Ojas Hospital, Panchkula, India \\ ${ }^{6}$ Department of Psychiatry, MONUSCO, Congo
}

\begin{abstract}
Introduction: According to the World Health Organisation (WHO), postpartum haemorrhage (PPH) is a leading cause of maternal mortality, accounting for $35 \%$ of maternal deaths worldwide. If blood loss is not assessed correctly and managed swiftly, it may rapidly result in fatality. The accurate assessment of blood loss is a guide to treatment and helps identify the cause of excessive blood loss. The present study was aimed at improving the accuracy of blood loss estimation during vaginal delivery by standardising the visual estimation method using a pre-weighed gauge and mops. This was correlated with measurement using the sterile Brass-V Drape under the buttock to determine the volume of blood loss.

Material and methods: The study was conducted on 500 gravidas with singleton pregnancy undergoing vaginal delivery in the Labour room of Umaid hospital, Dr S.N. Medical College, Jodhpur (Rajasthan), to estimate and compare the accuracy of blood loss occurring during vaginal delivery using visual estimation (standardised) and Brass- $\mathrm{V}$ Drape method. The difference in estimation of blood loss by the two methods up to $100 \mathrm{ml}$ was not considered significant in our study because this difference is unlikely to have any impact on maternal health.

Results: The mean blood loss in our study by standardised visual estimation method was $155.36 \pm 54.75 \mathrm{ml}$, and by Brass-V Drape estimation method it was $213.57 \pm 79.08 \mathrm{ml}$. The mean difference of blood loss in the two methods was 58.21 (213.57-155.36) $\mathrm{ml}$. For vaginal blood loss up to $200 \mathrm{ml}$ and up to $400 \mathrm{ml}$, the underestimation of blood loss by the standardised visual method was $41.9 \mathrm{ml}$ and $99.34 \mathrm{ml}$, respectively. However, when the loss was more than $500 \mathrm{ml}$, the underestimation was $198 \mathrm{ml}$. Therefore, this trend is indicative of the fact that with the increase in blood loss, the inaccuracy of the standardised visual estimation also increases.

Conclusions: Although the Brass-V Drape estimation method is the gold standard, the standardised visual blood loss estimation method is more practical, economical, readily available, easy to understand, and can be implemented with just a minimum of training. It is definitely an appealing method of blood loss estimation for all healthcare providers at facilities dealing with childbirth. For normal vaginal deliveries, except for those with massive blood loss, standardised visual blood loss estimation should be recommended as a routine method even in remote and peripheral areas by almost all levels of health care providers.

Key words: blood transfusion, obstetrics, blood loss.
\end{abstract}




\section{Introduction}

The period between the birth of the baby and expulsion of the placenta and membranes is the third stage of labour. Blood loss during this period and immediately thereafter depends on how well the placenta separates from the uterine wall and how well the uterus contracts to close the vascular channels in the placenta bed. Blood loss during delivery is physiological and does not lead to later problems except for women who are already anaemic. The major complication associated with this stage is postpartum haemorrhage.

Gyte in 1992 suggested that blood loss at birth is physiologically normal and is a part of the mechanism that brings the mother's blood volume back to its nonpregnant level [1]. According to the World Health Organisation (WHO), postpartum haemorrhage $(\mathrm{PPH})$ is defined as bleeding from the genital tract in excess of $500 \mathrm{ml}$ after vaginal delivery of the baby: postpartum haemorrhage (PPH) minor: $500-1000 \mathrm{ml}$, PPH major: over $1000 \mathrm{ml}$ (moderate $1000-2000 \mathrm{ml}$ and severe $>2000 \mathrm{ml}$ ).

The American College of Obstetricians and Gynaecologists (ACOG) define postpartum haemorrhage as excessive bleeding from the genital tract causing a haematocrit drop of more than $10 \%$ requiring immediate transfusion. Postpartum haemorrhage is sufficient to affect the general condition of the mother, which can be shown clinically by tachycardia and hypotension. Morbidity following PPH varies from simple to severe, such as the patient being vulnerable to anaemia, prolonged hospital stay, difficulties in establishing breast feeding, DIC, shock, acute renal failure, multiple organ dysfunction, sepsis, or death.

According to the World Health Organisation, $60 \%$ of maternal deaths in developing countries are due to $\mathrm{PPH}$, accounting for more than 100,000 maternal deaths per year [2]. $\mathrm{PPH}$ is a complication in $5 \%$ to $10 \%$ of all deliveries and is currently one of the leading causes of maternal death worldwide [3]. PPH continues to be alarming for birth attendants because it can be uncontrolled. Postpartum haemorrhage is the primary cause of morbidity and mortality in obstetrics and the most important cause of admission for postpartum women in the intensive care unit [4].

Because of different diagnosing criteria, the incidence of $\mathrm{PPH}$ is variable. According to a systemic review, the prevalence of PPH with $>500 \mathrm{ml}$ of blood loss was $2.6 \%$ in Asia, 6.3\% in North America and Europe, 8.9\% in Latin America and the Caribbean, and $10.5 \%$ in Africa [5]. In India, the incidence of PPH is $2-4 \%$ with vaginal delivery [6]. In the United States the pregnancy-related mortality ratio was 17.3 deaths per 100,000 live births in 2013, and approximately $11.4 \%$ of these deaths were due to $\mathrm{PPH}$ [7].

In India, the incidence of maternal death due to $\mathrm{PPH}$ is $25.6 \%$ [8]. In rural India, maternal mortality rates due to $\mathrm{PPH}$ are 350 to 650 per 100,000 live births, accounting for the world's highest number of maternal deaths per year [9]. In November 2003, FIGO and ICM issued a joint statement declaring the reduction of $\mathrm{PPH}$ an integral component of the Safe Motherhood global initiative.
Assessment of postpartum blood loss is difficult, particularly after vaginal birth, due to physiological adaptation to pregnancy including an increase in plasma volume and haemodilution providing a reserve of circulatory volume, and signs of haemorrhage may be delayed $[10,11]$. Assessment of blood loss after delivery is important because active intervention in the "golden hour" is crucial to prevent maternal morbidity and mortality [12]. Delays in treating postpartum haemorrhage are because of late symptom recognition and timely accurate diagnosis $[13,14]$, due to lack of clinical experience in accessing the accurate blood loss following PPH, which may lead to underestimation by up to $50 \%$ [15]. Delays in the diagnosis and treatment of PPH may result from an underestimation of blood loss at delivery. PPH, if not assessed correctly and managed swiftly, can result in a healthy woman becoming critically ill in few minutes and can be fatal.

Risk of haemorrhage is always present at birth, but early diagnosis of postpartum haemorrhage and implementation of preventive and curative measures as soon as possible can avoid the risks associated with delay. Therefore, blood loss estimation at delivery is crucial because the delay in recognising PPH can cost a woman her life. However, accurate measurement of blood loss is difficult. Blood loss quantification is not only important for immediate management, but also necessary to measure the incidence of haemorrhage.

Timely management of $\mathrm{PPH}$ requires quantification, so that mortality and morbidity can be reduced. For that, we can have several methods to quantify postpartum vaginal blood loss, and the details are as mentioned below: clinical assessment, visual estimation, standardised visual estimation, direct collection (Brass V drape), gravimetric estimation, photometry, venous blood sampling, dye dilution techniques for plasma volume measurement.

With this background, this study was conducted to estimate and compare the accuracy of blood loss occurring during vaginal delivery using visual estimation (standardised) and Brass-V Drape method.

\section{Material and methods}

\section{Study design}

Hospital-based descriptive observational study.

\section{Study location}

Labour room of Umaid hospital, Dr S.N. Medical College, Jodhpur (Rajasthan).

\section{Study duration}

Subjects were recruited after approval of the Ethics Committee until a sample size of 500 was achieved.

\section{Inclusion criteria}

All gravidas with singleton pregnancies undergoing vaginal delivery at this institute were included in the study.

\section{Exclusion criteria}

1. Preterm deliveries. 
Table I. Interpretation of $\kappa$ value

\begin{tabular}{|l|c|}
\hline Value of $\kappa$ & Strength of agreement \\
\hline$<0.20$ & Poor \\
\hline $0.21-0.40$ & Fair \\
\hline $0.41-0.60$ & Moderate \\
\hline $0.61-0.80$ & Good \\
\hline $0.81-1.00$ & Very good \\
\hline
\end{tabular}

2. Pregnancy is associated with co-morbidities like preeclampsia, eclampsia, severe anaemia, heart disease, thyroid, and liver disease.

3. All planned/emergency caesarean section, antepartum haemorrhage.

4. All women undergoing operative vaginal delivery.

\section{Data collection}

Data from all women in this study undergoing normal vaginal delivery were collected in a preset predesigned performa including all required details. Data from all subjects was collected by the same researcher to avoid bias. All women were provided with a Brass-V Drape under-the-buttock drape after delivery of the baby and before delivery of placenta. The Brass-V Drape was covered by a sheet. At the completion of the third stage of labour and just before shifting the mother from the labour table, blood loss was estimated. Blood loss estimation was first done by the routine standardised visual estimation method used at our institute, and then the actual amount of blood collected in the Brass-V Drape was noted by the observer. We compared both methods of blood loss estimation, and the mean difference of blood loss up to $100 \mathrm{ml}$ between both methods was not considered substantial enough because this difference would be unlikely to have an impact on maternal health.

\section{Data analysis}

Qualitative data variables were expressed using frequency and percentage. Continuous variables were summarised as median, range, mean, and standard deviation. All statistical analysis was done using Epi info statistical software. An inter-rater agreement statistic ( $\kappa$, kappa) was calculated with $95 \%$ confidence interval.

The $\kappa$ value was interpreted as shown in Table I.

\section{Methodology}

For standardised visual estimation of blood loss

Earlier, blood loss was quantified based only on visual approximation, which was inaccurate in up to $50 \%$ of cases, but to make it more reliable, we have a standardised a pictorial visual blood loss estimation guideline in place at our institute, and the estimation was done accordingly (Figure 1). To minimise the bias in results during standardised visual estimation, we covered the Brass-V Drape with sheets. According to the standardised visual guide chart:

- Maternity pad $(10 \times 5 \mathrm{~cm})$ fully soaked standing for $100 \mathrm{ml}$ blood,
- Roller gauge packing fully soaked equals $100 \mathrm{ml}$,

- Large (45 × $45 \mathrm{~cm} 12$ ply) fully soaked swab stood for $350 \mathrm{ml}$,

- $1 \mathrm{~kg}$ of soaked swabs means $1000 \mathrm{ml}$,

- $50 \mathrm{~cm}$ diameter floor spill amounts to $500 \mathrm{ml}$,

- $75 \mathrm{~cm}$ diameter floor spill equals $1000 \mathrm{ml}$,

- $100 \mathrm{~cm}$ diameter floor spill means $1500 \mathrm{ml}$,

- Vaginal PPH limited to the bed is $1000 \mathrm{ml}$,

- $\quad$ PPH overflow from the bed stood for $2000 \mathrm{ml}$.

\section{Estimation using Brass-V Drape}

We used a Brass-V Drape with a graduated pouch under the buttocks for blood loss estimation (Figure 2). To avoid contamination of amniotic fluid, the Brass-V Drape was used immediately after delivery of the baby and before delivery of the placenta. It consists of a funnelled and calibrated collecting pouch attached to a plastic sheet that is placed under the woman's buttocks immediately after delivery of baby. The gauges and pads (soaked in blood) were used for cleaning and repairing of the episiotomy, which were put in the Brass-V Drape for accurate measurement of blood loss. Blood spilled on the sheet under the buttocks was also included in the Brass-V Drape estimation.

\section{Results}

After initial screening on the basis of inclusion and exclusion criteria of the study, 500 pregnant women were enrolled and evaluated by detailed history taking, and clinical and obstetric examination. Out of 500 deliveries at our institute, only 5 women had mild PPH. Vaginal blood loss estimation was done by the standardised visual blood loss estimation method and the Brass-V Drape estimation method, and the results were compared.

Table II depicts mean, median, and range of vaginal blood loss using both methods. The mean value of blood loss using the standardised visual method was found to be $153.36 \pm 54.75 \mathrm{ml}$ while it was $213.57 \pm 79.08 \mathrm{ml}$ by Brass- $\mathrm{V}$ Drape estimation.

The comparison of vaginal blood loss along with the mean difference of blood loss between both methods using various variables is shown in Table III. The difference of mean blood loss by these two methods in the age groups 18-25 years, 26-30 years, and $>30$ years was $54.78 \mathrm{ml}, 66.14 \mathrm{ml}$, and $79.16 \mathrm{ml}$, respectively, suggesting an increasing difference in amount with rising age. Blood loss was more in unbooked cases, multiparous, underweight, obese, uneducated, urban, and low socioeconomic status women.

Table IV shows the comparison between the standardised visual blood loss estimation method and Brass- $\mathrm{V}$ Drape method. There were 5 women who had blood loss $>500 \mathrm{ml}$ as estimated by Brass-V Drape method. However, none of the women had blood loss $>500 \mathrm{ml}$ as per the visual blood loss estimation method. Standardised visual estimation methods had fair agreement (Cohen's $\kappa$ coefficient 0.307 ) up to an average blood loss of $500 \mathrm{ml}$ by vaginal delivery. 


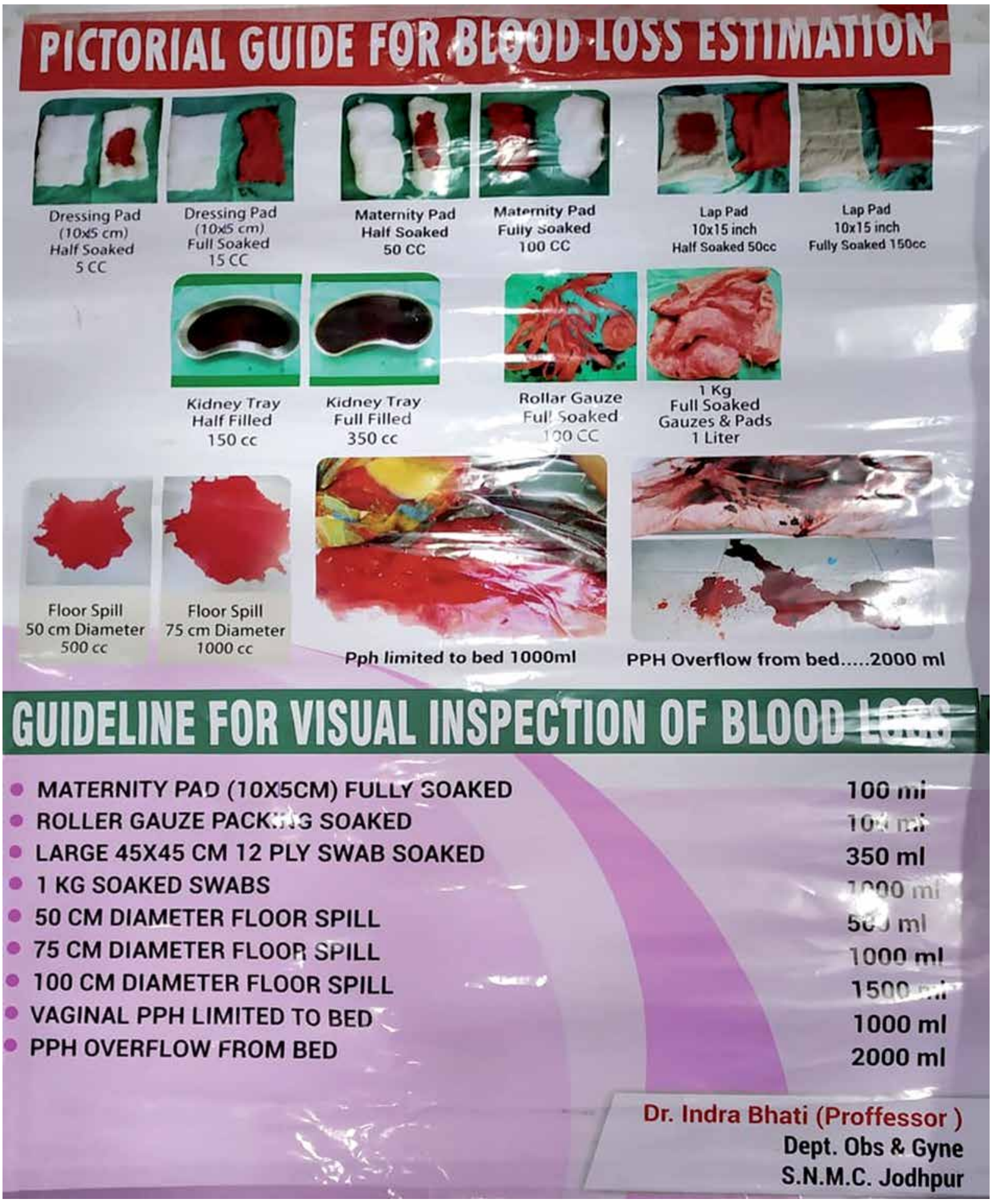

Figure 1. Standardised visual blood estimation method

\section{Discussion}

According to the WHO, $\mathrm{PPH}$ is a leading cause of maternal mortality accounting for $35 \%$ of maternal deaths worldwide. Most deaths occur in low- and middle-income countries (99\%) compared with only $1 \%$ in industrialised nations. If managed in a timely and efficient manner, the mortalities due to PPH can be curbed. The accurate assessment of blood loss is a guide to the treatment and identification of the causes of excessive blood loss. This helps in early diag- nosis and treatment thus reducing morbidity and mortality associated with excessive blood loss. The present study was aimed at improving the accuracy of blood loss estimation during vaginal delivery by standardising the visual estimation method using a pre-weighed gauge and mops. This was correlated with measurements using a sterile Brass-V Drape under the buttocks to determine the volume of blood loss.

The prevalent child-bearing age in India is between 21 and 30 years. The mean age of women in the present study was 23.90 years. Considering different age groups, the 


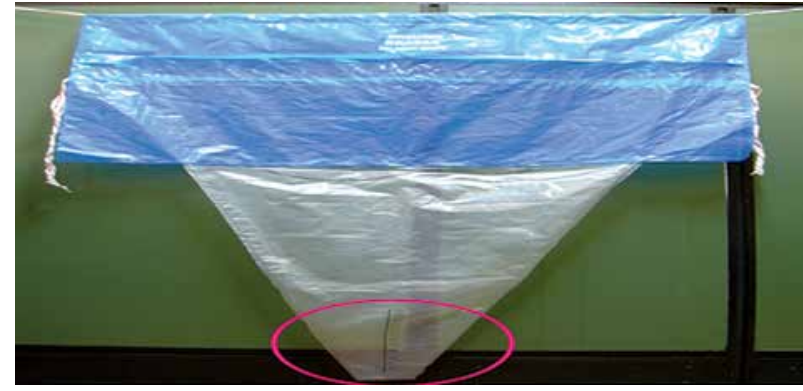

Figure 2. Brass-V Drape method

Table II. Mean, median, and range of blood loss following vaginal delivery using two methods

\begin{tabular}{|l|c|c|}
\hline Statistical analysis & $\begin{array}{c}\text { Standardised visual } \\
\text { blood loss [ml] }\end{array}$ & $\begin{array}{c}\text { Brass-V Drape } \\
\text { estimate [ml] }\end{array}$ \\
\hline Mean \pm SD & $155.36 \pm 54.75$ & $213.57 \pm 79.08$ \\
\hline Median & 150 & 200 \\
\hline Range & $80-400$ & $100-600$ \\
\hline
\end{tabular}

vaginal blood loss estimation was higher by Brass-V Drape method as compared to the standardised visual blood loss estimation.

The increase in blood loss was correlated with age. There was an increase in the incidence of postpartum vaginal blood loss with increasing maternal age in the present study, from $147.58 \pm 46.62 \mathrm{ml}$ in women between the age of 18 and 25 years to $198.75 \pm 82.32 \mathrm{ml}$ in women who were above the age of 30 years. Our results were comparable with the studies of Girault et al. [16], Kramer et al. [17], and the Blomberg study [18]. The difference of mean blood loss by these two methods in the age group 18-25 years, 26-30 years, and $>30$ years was $54.78 \mathrm{ml}, 66.14$, and $79.16 \mathrm{ml}$, respectively, suggesting an increasing difference in amount with rising age.

According to the locality, 303 (60.6\%) women were from rural areas and 197 (39.4\%) women were from urban areas. The reason for the large number of rural women can be attributed to the fact that ours is the first referral hospital of the entire Western Rajasthan, and financial constraints can be another contributing factor. The volume of postpartum blood loss in the present study was higher in urban than in rural women. The results were contrary to the results of the studies Varadha [19] and Temesgen [20]. This could be because most of the women from the urban areas were actually from the slums and low socio-economic families. The difference of mean blood loss by these two methods in women from rural and urban areas was $55.44 \mathrm{ml}$ and $62.49 \mathrm{ml}$, respectively.

Our study had more (booked cases) women 337 (67.4\%) than unbooked cases 163 (32.6\%). Booked women were defined as those who had at-least three antenatal visits at our center, while unbooked women were those who have no prenatal care at all throughout the pregnancy, those who registered at our unit but had less than two antenatal clinic visits, and patients referred as emergency from other facilities. The reason behind the large number of booked caseswas attributed to the fact that in this present study we had excluded women with complications like anaemia, pre-eclampsia, ec- lampsia, diabetes, etc. because our institute is a tertiary care hospital, so most of the women were referred from rural areas, who were otherwise more vulnerable to the above-mentioned complications. The average blood loss in the present study was more in unbooked cases. Our results are comparable with the studies of Varadha [19] and Gani and Ali [21] but contrary to the findings of Temesgen [20] in which more blood loss was found in booked women. The difference of mean blood loss by these two methods in booked and unbooked category was $56.65 \mathrm{ml}$ and $61.41 \mathrm{ml}$, respectively. Average blood losses in women who were ANC booked were less when compared to unbooked women.

In present study, 274 (54.8\%) women were multipara and 226 (45.2\%) were primigravida. We found that post-partum vaginal blood loss was more in multipara than in primigravida, which was in concurrence with Aude, Girault et al. [16], Kramer et al. [17], the Blomberg study [18], Temesgen [20], and Gani and Ali [21]. Higher parity is a risk factor for blood loss, and this was supported by various studies. The difference of mean blood loss by these two methods in women who were primigravida and multipara is $54.71 \mathrm{ml}$ and 61.12 $\mathrm{ml}$, respectively. With each pregnancy, some uterine muscle fibres are replaced by fibrous tissue, so the retraction power of the uterus decreases, which could be a principal factor for the occurrence of PPH.

We found that vaginal blood loss was greater in uneducated women and in those with low socioeconomic status when compared to educated, high socioeconomic status women. Moreover, women belonging to nuclear families had a greater amount of vaginal blood loss when compared to women who had joint families. Justification for this may be due to the presence of nutritional deficiency and ignorance of health; also, such women had frequent childbirths due to unawareness of family planning services. Comparable data on these factors were not available due to lack of research.

In the present study, 83 (16.6\%) out of 500 women were addicted to smoking/tobacco chewing. Our study results show that there was more blood loss in mothers who were addicted (smoker/tobacco). Similar results were found by the studies of Kramer et al. [17] and Contreras et al. [22]. The difference of mean blood loss by these two methods in women who were addicted and not addicted is $60.26 \mathrm{ml}$ and $57.77 \mathrm{ml}$, respectively.

We found that both overweight and underweight women had a tendency of high blood loss at delivery compared to normal-weight women. Our results were supported by the results of the Blomberg study [18], Fyfe et al. [23], and Ibrahim et al. [24].

However, our results were contrary to the results found by Butwick et al. [25], who found only a very small effect of maternal BMI on postpartum haemorrhage. The difference of mean blood loss by these two methods in women with normal BMI, obese, pre-obese, and underweight was $53.57 \mathrm{ml}, 94.61 \mathrm{ml}, 77.3 \mathrm{ml}$, and $87.78 \mathrm{ml}$, respectively.

We found that there was slightly more blood loss in women who delivered with an episiotomy compared to delivery without episiotomy, which is similar to the findings 
Table III. Comparison of vaginal blood loss estimation by both methods using various variables

\begin{tabular}{|c|c|c|c|c|}
\hline Variables & No. of patients & $\begin{array}{l}\text { Standardised visual blood } \\
\text { loss (mean } \pm \text { SD) [ml] }\end{array}$ & $\begin{array}{l}\text { Brass-V Drape estimate } \\
\text { (mean } \pm \text { SD) [ml] }\end{array}$ & $\begin{array}{l}\text { Difference of mean blood } \\
\text { loss [ml] }\end{array}$ \\
\hline \multicolumn{5}{|l|}{ Age [years]: } \\
\hline $18-25$ & 376 & $147.58 \pm 46.62$ & $202.36 \pm 65.88$ & 54.78 \\
\hline $26-30$ & 100 & $174.71 \pm 65.37$ & $240.85 \pm 97.20$ & 66.14 \\
\hline$>30$ & 24 & $198.75 \pm 82.32$ & $277.91 \pm 122.65$ & 79.16 \\
\hline \multicolumn{5}{|l|}{ Residence: } \\
\hline Rural & 303 & $152.14 \pm 52.92$ & $207.58 \pm 74.99$ & 55.44 \\
\hline Urban & 197 & $160.45 \pm 57.25$ & $222.94 \pm 84.43$ & 62.49 \\
\hline \multicolumn{5}{|l|}{ Booking status: } \\
\hline Booked & 337 & $152.89 \pm 51.52$ & $209.54 \pm 73.22$ & 56.65 \\
\hline Unbooked & 163 & $160.61 \pm 60.79$ & $222.02 \pm 89.81$ & 61.41 \\
\hline \multicolumn{5}{|l|}{ Parity: } \\
\hline Primigravida & 226 & $145.80 \pm 46.47$ & $200.51 \pm 64.34$ & 54.71 \\
\hline Multipara & 274 & $163.46 \pm 59.75$ & $224.58 \pm 88.28$ & 61.12 \\
\hline \multicolumn{5}{|c|}{ Educational status: } \\
\hline Educated & 340 & $149.94 \pm 49.55$ & $205.79 \pm 69.68$ & 55.85 \\
\hline Uneducated & 160 & $166.60 \pm 62.82$ & $229.60 \pm 93.81$ & 63 \\
\hline \multicolumn{5}{|l|}{ Occupation: } \\
\hline Housewife & 335 & $149.94 \pm 49.55$ & $205.79 \pm 69.68$ & 55.85 \\
\hline Working & 165 & $166.60 \pm 62.82$ & $229.60 \pm 93.81$ & 63.6 \\
\hline \multicolumn{5}{|l|}{ Type of family: } \\
\hline Single & 133 & $169.13 \pm 63.06$ & $232.64 \pm 91.73$ & 63.51 \\
\hline Joint & 367 & $150.21 \pm 50.40$ & $206.40 \pm 72.62$ & 56.19 \\
\hline \multicolumn{5}{|c|}{ Socioeconomic status: } \\
\hline Low & 78 & $173.97 \pm 63.45$ & $240.60 \pm 96.86$ & 66.63 \\
\hline Medium & 422 & $151.72 \pm 52.17$ & $208.25 \pm 74.08$ & 56.53 \\
\hline \multicolumn{5}{|l|}{ Addiction: } \\
\hline Yes & 83 & $161.92 \pm 57.92$ & $222.18 \pm 84.74$ & 60.26 \\
\hline No & 417 & $154.09 \pm 54.08$ & $211.86 \pm 77.91$ & 57.77 \\
\hline \multicolumn{5}{|l|}{ BMI: } \\
\hline Normal & 419 & $146.83 \pm 47.09$ & $200.40 \pm 64.53$ & 53.57 \\
\hline Obese & 13 & $216.15 \pm 76.76$ & $310.76 \pm 118.64$ & 94.61 \\
\hline Pre-obese & 50 & $199.8 \pm 67.23$ & $277.1 \pm 101.36$ & 77.3 \\
\hline Underweight & 18 & $189.44 \pm 69.40$ & $277.22 \pm 120.58$ & 87.78 \\
\hline \multicolumn{5}{|l|}{ Newborn sex: } \\
\hline Male & 237 & $155.37 \pm 55.11$ & $213.05 \pm 80.07$ & 57.68 \\
\hline Female & 263 & $155.39 \pm 54.51$ & $214.04 \pm 78.32$ & 58.65 \\
\hline \multicolumn{5}{|l|}{ Episiotomy: } \\
\hline Yes & 377 & $155.39 \pm 54.51$ & $247.31 \pm 102.95$ & 91.92 \\
\hline No & 123 & $148.16 \pm 47.53$ & $202.70 \pm 66.29$ & 54.54 \\
\hline \multicolumn{5}{|c|}{ Additional uterotonics: } \\
\hline Yes & 52 & $272.30 \pm 44.44$ & $392.30 \pm 67.58$ & 120 \\
\hline No & 448 & $141.96 \pm 36.96$ & $193.05 \pm 48.60$ & 51.09 \\
\hline \multicolumn{5}{|l|}{ Baby weight $[\mathrm{kg}]$ : } \\
\hline $2-2.5$ & 162 & $150.61 \pm 5.34$ & $205.09 \pm 68.08$ & 54.48 \\
\hline $2.5-3$ & 213 & $157.52 \pm 55.56$ & $218.09 \pm 83.32$ & 60.57 \\
\hline$>3$ & 125 & $157.84 \pm 57.60$ & $216.68 \pm 84.35$ & 54.84 \\
\hline
\end{tabular}


Table III. Cont.

\begin{tabular}{|l|c|c|c|c|}
\hline Variables & No. of patients & $\begin{array}{c}\text { Standardised visual blood } \\
\text { loss (mean } \pm \text { SD) }[\mathrm{ml}]\end{array}$ & $\begin{array}{c}\text { Brass-V Drape estimate } \\
\text { (mean } \pm \text { SD) [ml] }\end{array}$ & $\begin{array}{c}\text { Difference of mean blood } \\
\text { loss [ml] }\end{array}$ \\
\hline Blood loss [ml]: & & & & 41.9 \\
\hline $100-199$ & 245 & $117.96 \pm 22.50$ & $159.86 \pm 16.40$ & 52.96 \\
\hline $200-299$ & 159 & $161.50 \pm 22.78$ & $214.46 \pm 24.42$ & 99.34 \\
\hline $300-399$ & 75 & $224.66 \pm 30.55$ & $324 \pm 28.99$ & 128.13 \\
\hline $400-499$ & 16 & $288.12 \pm 20.07$ & $416.25 \pm 22.47$ & 198 \\
\hline
\end{tabular}

of Ashouri et al. [26] and Lam et al. [27]. The variation of mean blood loss by these two methods in women with episiotomy and without episiotomy were $91.92 \mathrm{ml}$ and $54.54 \mathrm{ml}$, respectively.

Our study shows that there was no significant difference in postpartum vaginal blood loss according to birth weight of the newborn, which was also supported by the study of Kramer et al. [17], who concluded that no significant difference in postpartum blood loss occurred due to birth weight of the newborn especially when their weight was below $4 \mathrm{~kg}$. However, blood loss was more when the birth weight was above $4 \mathrm{~kg}$. Fyfe et al. [23] in their study showed that the risk of postpartum haemorrhage increased when the birth weight was more than $3.5 \mathrm{~kg}$. The mean blood loss differences by these two methods in women with baby weight $2-2.5 \mathrm{~kg}$, $2.5-3 \mathrm{~kg}$, and > $3 \mathrm{~kg}$ were $54.48 \mathrm{ml}, 60.57 \mathrm{ml}$, and $54.84 \mathrm{ml}$, respectively.

The difference in estimation of blood loss by the two methods up to $100 \mathrm{ml}$ was not considered significant in our study because this difference is unlikely to impact maternal health. We have observed that in women who had blood loss up to $200 \mathrm{ml}$ and $400 \mathrm{ml}$, the difference between both methods was $41.9 \mathrm{ml}$ and $99.34 \mathrm{ml}$, respectively. Furthermore, where the blood loss was in the range of 400-500 ml and $>500 \mathrm{ml}$, the difference goes up to $128.13 \mathrm{ml}$ and $198 \mathrm{ml}$, respectively. The mean blood loss in our study by standardised visual estimation method was 155.36 $\pm 54.75 \mathrm{ml}$ and by Brass-V Drape estimation method was $213.57 \pm 79.08 \mathrm{ml}$. The mean difference of blood loss in the two methods was $58.21(213.57-155.36) \mathrm{ml}$. Our findings with respect to the mean differences in both methods were supported by a number of other studies [28-33]. The prevalence of primary PPH as estimated with Brass-V Drape method was $1 \%$ against $0 \%$ by standardised visual estimation. For every 500 women, we would be actually missing five women with mild PPH by using the standardised visual methods. The range of blood loss estimated by the standardised visual method and Brass-V Drape method was $80-400 \mathrm{ml}$ and 100$600 \mathrm{ml}$, respectively, suggesting that up to $500 \mathrm{ml}$ blood loss estimation was comparable by the two methods.

Standardised visual estimation had fair agreement (Cohen's $\kappa$ coefficient 0.307 ) up to an average blood loss of $500 \mathrm{ml}$ by vaginal delivery. However, with the increase in blood loss (more than $500 \mathrm{ml}$ ), the discrepancy in standardised visual method also increases, but barring such cases of massive blood loss, the standardised visual method can be employed without any hesitation.

\section{Conclusions}

Postpartum haemorrhage is the most common cause of serious blood loss in obstetrics. If blood loss is not assessed correctly and managed swiftly, it may result in a fatality and can have a high chance of a healthy women becoming

Table IV. Comparison between visual blood loss estimation method and Brass-V Drape method

\begin{tabular}{|c|c|c|c|c|c|c|c|}
\hline \multirow{2}{*}{$\begin{array}{l}\text { Brass V drape } \\
\text { estimate [ml] }\end{array}$} & \multicolumn{6}{|c|}{ Standardised visual blood loss [ml] } & \multirow[t]{2}{*}{ Total } \\
\hline & $0-100$ & $101-200$ & $201-300$ & $301-400$ & $401-499$ & $>500$ & \\
\hline $0-100$ & 00 & 02 & 00 & 00 & 00 & 00 & 02 \\
\hline $101-200$ & 136 & 206 & 00 & 00 & 00 & 00 & 342 \\
\hline $201-300$ & 00 & 95 & 07 & 00 & 00 & 00 & 102 \\
\hline $301-400$ & 00 & 00 & 43 & 00 & 00 & 00 & 43 \\
\hline $401-499$ & 00 & 00 & 06 & 00 & 00 & 00 & 06 \\
\hline$\geq 500$ & 00 & 00 & 00 & 05 & 00 & 00 & 05 \\
\hline Total & 136 & 303 & 56 & 05 & 00 & 00 & 500 \\
\hline \multicolumn{3}{|l|}{ Weighted $\kappa$} & \multicolumn{5}{|c|}{0.307} \\
\hline \multicolumn{3}{|l|}{ Standard error } & \multicolumn{5}{|c|}{0.015} \\
\hline \multicolumn{3}{|l|}{$95 \% \mathrm{Cl}$} & \multicolumn{5}{|c|}{$0.276-0.338$} \\
\hline
\end{tabular}


critically ill within minutes. Blood loss can be measured by a variety of methods, most of which are cumbersome and impractical in general clinical practice. In routine blood loss it is usually estimated by subjective visual quantification, which is generally based upon prior clinical experience. The conclusions drawn from the study are as follows:

1. The mean blood loss by Brass-V Drape method was 213.57 $\pm 79.08 \mathrm{ml}$ against a mean of $153.36 \pm 54.75 \mathrm{ml}$ blood loss estimated by the standardised visual estimation method, and the mean difference of blood loss between both methods was $58.21 \mathrm{ml}$. Prevalence of primary PPH as estimated with Brass-V Drape method was $1 \%$ against the zero percent by standardised visual estimation.

2. Our findings also indicate that in all these instances where the blood loss was up to $200 \mathrm{ml}$ and $400 \mathrm{ml}$, the underestimation of blood loss by the standardised visual method was $41.9 \mathrm{ml}$ and $99.34 \mathrm{ml}$, respectively. However, when the loss was more than $500 \mathrm{ml}$, the underestimation was $198 \mathrm{ml}$. Therefore, this trend is indicative of the fact that with the increase in blood loss, the inaccuracy of the standardised visual estimation also increases.

3. The reported difference of $58.21 \mathrm{ml}$ may not be clinically meaningful in women sustaining small blood loss. However, with a blood loss of more than $500 \mathrm{ml}$, underestimation of the standardised visual method may well have a significant impact on maternal health. Therefore, prompt detection of PPH is essential for timely institution of definitive management or intervention.

4. Brief educational training for standardisation of the visual estimation of blood loss may be helpful in everyday practice to more accurately estimate blood loss and recognise patient risk for haemorrhage-related complications because the appearance of clinical signs due to blood loss may be too late.

Hence, with this study we conclude that although Brass-V Drape estimation method is the gold standard, the standardised visual blood loss estimation method, which is more practical, economical, readily available, easy to understand, and can be practiced with just a minimum of training, is definitely an appealing method of blood loss estimation by all healthcare providers at each and every facility dealing with childbirth.

\section{Recommendations}

1. To further validate the results of standardised visual blood loss estimation, such results ought to be compared with laboratory tests like haematocrit estimation and final outcome of patients.

2. For normal vaginal deliveries, except for those with massive blood loss, standardised visual blood loss estimation can be recommended as the routine method even in remote and peripheral areas by almost all levels of health care providers.

3. Larger studies including women with high-risk pregnancies and those sustaining complications like shock, the need for blood transfusion, and operative interventions should be conducted to further validate the two methods.

\section{Strengths of study}

1. Reasonable sample size.

2. Vaginal blood loss estimation by both methods appears comparable.

3. Standardised visual estimation methods can be easily taught and used by any level of health facility, even by primary health care workers with minimal training.

\section{Limitations}

1. Results were not compared with laboratory methods of estimation like haematocrit measurement and clinical symptoms of women.

2. There was low average blood loss, so the difference between the two methods in massive haemorrhage could not be compared.

3. The size and material of the soaking gauges, roller gauges, laparotomy sponge, and maternity pads used to standardise the visual estimation of blood loss may be different in each institution, and hence each institution needs to prepare their own guidelines with locally used material.

\section{References}

1. Gyte G. The significance of blood loss at delivery. MIDIRS Midwifery Digest 1992; 2: 88-92.

2. World Health Organization (WHO). Reducing the global burden: postpartum haemorrhage. Making Pregnancy Safer 2007; 1: 8.

3. Deneux-Tharaux C, Bonnet MP, Tort J. epidemiology of postpartum hemorrhage. J Gynaecol Obstet Biol Reprod 2014; 43: 936-50.

4. Hill JA, Fadel HE, Nelson RM, Nelson GH. Blood loss at vaginal delivery. South Med J 1986; 79: 188-92.

5. Carroli G, Cuesta C, Abalos E, Gulmezoglu AM. Epidemiology of postpartum haemorrhage: a systematic review. Best Pract Res Clin Obstet Gynaecol 2008; 22: 999-1012.

6. Amy JJ. Severe postpartum haemorrhage: a rational approach. Natl Med J India 1998; 11: 86-8.

7. Coeytaux F, Bingham D, Strauss N. Maternal mortality in the United States: a human rights failure. Contraception 2011; 83: 189-93.

8. Kaurtz AM, Hugues JM, Grinies DA, et al. Cause of maternal mortality in United States. Obstet Gynecol 1985; 65: 605-12.

9. WHO U. UNFPA: Maternal Mortality in 2000: Estimates developed by WHO, UNICEF and UNFPA. Geneva, Department of Reproductive Health and Research, WHO. 2004. WHO U. UNFPA: Maternal Mortality in 2000: Estimates developed by WHO, UNICEF and UNFPA. Geneva, Department of Reproductive Health and Research, WHO. 2004.

10. Carbillon L, Uzan M, Uzan S. Pregnancy, vascular tone, and maternal hemodynamics: a crucial adaptation. Obstet Gynecol Survey 2000; 55: 574-81.

11. Lund CJ, Donovan JC. Blood volume during pregnancy: significance of plasma and red cell volumes. Am J Obstet Gynaecol 1967; 98: 393-403.

12. Fauziah SF, Widyawati MN, Amartha TA. Methods of postpartum blood loss measurement in Indonesia should be modified for better accuracy: a literature review. Proceedings of the International Conference on Applied Science and Health 2017; 2: 54-62. 
13. Quantification of Blood Loss: AWHONN Practice Brief Number 1. J Obstet Gynecol Neonatal Nurs 2015; 44: 158-60.

14. Schorn MN. Measurement of blood loss: review of the literature. J Midwif Women's Health 2010; 55: 20-7.

15. Society of obstetricians and gynaecologists of Canada. Prevention and management of postpartum haemorrhage: SOGC clinical practice guideline No 88 .

16. Girault A, Deneux-Tharaux C, Sentilhes L, Maillard F, Goffinet F. Undiagnosed abnormal postpartum blood loss: incidence and risk factors. PLoS One 2018; 13: e0190845.

17. Kramer MS, Dahhou M, Vallerand D, Liston R, Joseph KS. Risk factors for postpartum hemorrhage: can we explain the recent temporal increase? J Obstet Gynaecol Can 2011; 33: 810-9.

18. Blomberg M. Maternal obesity and risk of postpartum hemorrhage. Obstet Gynecol 2011; 118: 561-8.

19. Varadha K. Prospective study of peripartum hysterectomy done over a 2 year period in hospitals attached to jjmmc davangere (Doctoral dissertation).

20. Temesgen MA. Magnitude of postpartum hemorrhage among women delivered at Dessie Referral Hospital, South Woll, Amhara Region, Ethiopia. J Women's Health Care 2017; 6: 4.

21. Gani GN, Ali AT. Prevalence and factors associated with maternal postpartum haemorrhage in Khyber Agency, Pakistan. J Ayub Med Coll Abbottabad 2013; 25: 81-5.

22. Contreras KR, Kominiarek MA, Zollinger TW. The impact of tobacco smoking on perinatal outcome among patients with gestational diabetes. J Perinatol 2010; 30: 319-23.

23. Fyfe EM, Thompson JM, Anderson NH, Groom KM, McCowan LM. Maternal obesity and postpartum haemorrhage after vaginal and caesarean delivery among nulliparous women at term: a retrospective cohort study. BMC Pregnancy Childbirth 2012; 12: 112 .

24. Ibrahim M, Chuah SC. Maternal obesity and the risk of primary postpartum haemorrhage. 10 year retrospective study in an Australian regional obstetric population. Eur J Obstet Gynecol Reproduct Biol 2016; 206: e157.

25. Butwick AJ, Abreo A, Bateman BT, et al. The effect of maternal body mass index on postpartum hemorrhage. Anesthesiology 2018; 128: 774-83.

26. Ashouri N, Kordi M, Tara F. Diagnostic value of risk nomogram for the prediction of postpartum hemorrhage following vaginal delivery. Evidence Based Care 2019; 9: 26-34.

27. Lam K, Wong H, Pun T. The practice of episiotomy in public hospitals in Hong. Hong Kong Med J 2006; 12: 94-8.

28. Lertbunnaphong T, Lapthanapat N, Leetheeragul J, Hakularb P, Ownon A. Postpartum blood loss: standardized visual estimation versus objective quantification with a novel birthing Brass $\mathrm{V}$ drape. Singapore Med J 2016; 57: 325-8.

29. Patel A, Goudar SS, Geller SE, et al. Brass V drape estimation vs. standardized visual assessment for estimating postpartum hemorrhage. Int J Gynecol Obstet 2006; 93: 220-4.

30. Ambardekar S, Shochet T, Bracken H, Coyaji K, Winikoff B. Calibrated delivery Brass $\mathrm{V}$ drape versus indirect gravimetric technique for the measurement of blood loss after delivery: a randomized trial. BMC Pregnancy Childbirth 2014; 14: 276.

31. Turpin CA, Osakunor DN, Owiredu WK. Accuracy of blood loss determination after vaginal delivery: standardized visual estima- tion versus calibrated measurement. J Adv Med Med Res 2015; 28: 1121-7.

32. Kodkany BS, Derman RJ, Sloan N. Pitfalls in assessing blood loss and decision to transfer. A textbook of postpartum hemorrhage. 2006.

33. Sasagawa E, de Buendia LE, Avendano GA, et al. A comparison of blood loss determination after vaginal delivery in el salvador: standardized visual estimation versus direct measurement. Int J Nurs Health Sci 2017; 4: 81. 